\title{
Essentiality and Transcriptome-Enriched Pathway Scores Predict Drug-Combination Synergy
}

\author{
Jin $\mathrm{Li}^{1}{ }^{1}$, Yang Huo ${ }^{2}$, Xue Wu $^{1}$, Enze Liu ${ }^{2}$, Zhi Zeng ${ }^{1}$, Zhen Tian ${ }^{1}$, Kunjie Fan ${ }^{1}{ }^{\circledR}$, \\ Daniel Stover ${ }^{3}$, Lijun Cheng ${ }^{1}$ and Lang $\mathrm{Li}^{1, *}$ \\ 1 Department of Biomedical Informatics, The Ohio State University, Columbus, OH 43202, USA; \\ jin.li@osumc.edu (J.L.); xue.wu@osumc.edu (X.W.); zhizeng@whu.edu.cn (Z.Z.); \\ Zhen.Tian@osumc.edu (Z.T.); Kunjie.Fan@osumc.edu (K.F.); Lijun.Cheng@osumc.edu (L.C.) \\ 2 School of Informatics and Computing, Indiana University, Indianapolis, IN 46202, USA; \\ yanghuo@iu.edu (Y.H.); enzeliu@iu.edu (E.L.) \\ 3 Division of Medical Oncology, Department of Medicine, The Ohio State University, \\ Columbus, OH 43202, USA; Daniel.Stover@osumc.edu \\ * Correspondence: Lang.Li@osumc.edu
}

Received: 21 July 2020; Accepted: 4 September 2020; Published: 7 September 2020

\begin{abstract}
In the prediction of the synergy of drug combinations, systems pharmacology models expand the scope of experiment screening and overcome the limitations of current computational models posed by their lack of mechanical interpretation and integration of gene essentiality. We therefore investigated the synergy of drug combinations for cancer therapies utilizing records in NCI ALMANAC, and we employed logistic regression to test the statistical significance of gene and pathway features in that interaction. We trained our predictive models using 43 NCI-60 cell lines, 165 KEGG pathways, and 114 drug pairs. Scores of drug-combination synergies showed a stronger correlation with pathway than gene features in overall trend analysis and a significant association with both genes and pathways in genome-wide association analyses. However, we observed little overlap of significant gene expressions and essentialities and no significant evidence that associated target and non-target genes and their pathways. We were able to validate four drug-combination pathways between two drug combinations, Nelarabine-Exemestane and Docetaxel-Vermurafenib, and two signaling pathways, PI3K-AKT and AMPK, in 16 cell lines. In conclusion, pathways significantly outperformed genes in predicting drug-combination synergy, and because they have very different mechanisms, gene expression and essentiality should be considered in combination rather than individually to improve this prediction.
\end{abstract}

Keywords: drug-combination synergy prediction; drug target; gene essentiality; gene expression; KEGG pathway

\section{Introduction}

High-throughput genomic analyses are changing the landscape of cancer diagnosis [1-7]. A recent clinical study at Johns Hopkins University [8] indicated genomic changes in 25-98\% of cancer patients that could be targeted using drugs approved by the US Federal Drug Administration (FDA) and under clinical trial investigation, with the report noting a median of four actionable genetic alterations. These striking results imply the need to consider multi-drug therapies in most cancer patients, and investigations such as the Personalized Oncology Study at the University of Michigan [7] and the Pediatric Cancer Precision Medicine Study at Indiana University [9] are evaluating recommendations for multi-drug and -target interventions.

The steady growth of research and development of multi-drug therapies during the last decade highlights the profound understanding of the cancer research and drug development communities of the 
complexity of cancer biology and disease. The number of FDA-approved multi-drug cancer therapies increased from one combination in 2007 to 15 in 2018, and data reported in https://clinicaltrials.gov/ reflect an increase in clinical studies of multi-drug cancer therapies for the same period-from 445 in 2007 to 798 in 2018. We have observed a similar trend in the pre-clinical cancer research community. PubMed data demonstrate an increase in the publication of in vitro or animal studies of multi-drug therapies for cancer from 12,341 in 2001 to 26,323 in 2018.

A drug combination effect (inhibition) on the cell viability can be either greater or lesser than their additive effect achieved by their individual use, resulting in synergistic or antagonistic interactions [10]. Those drug combinations working synergistically require much lower doses of each drug to achieve the same effect on cell viability and are therefore much more appealing for clinical use.

High-throughput preclinical approaches that include both drug-screening experiments and computational biology approaches are crucial to identify synergistic drug combinations. An exponentially growing number of combination drugs, heterogeneous disease mechanisms, and cell cultural models challenge the capacity of experimentation to assess drugs [11], so rapid and efficacious computational approaches could play a critical complementary role in their evaluation [12].

Sources of data in the public domain regarding large-scale screenings of drug combinations include those of the National Cancer Institute (NCI), Merck \& Co., Inc., and AstraZeneca in partnership with the Sanger Institute. The NCI ALMANAC (A Large Matrix of Anti-Neoplastic Agent Combinations) database comprises more than 5000 drug pairs that utilize 104 drugs in $60 \mathrm{NCI}$ cancer cell lines [13], while the Merck \& Co. dataset screens 583 drug combinations in 39 cancer cell lines [11], and the drug-combination dataset compiled by AstraZeneca/Sanger for the DREAM (Dialog for Reverse Engineering Assessments and Methods) Challenge comprises 910 combinations across 85 cancer cell lines, but it does not include drug names [14].

Computational approaches to model and predict the synergy of drug combinations include machine-learning methods (DeepSynergy [15]; random forest (RF); extreme gradient boosting (XGBoost) [16]; and graph convolutional network (GCN) [17]), network methods [18,19], and systems biology methods $[10,20,21]$. Though these computational biology models differ in their analytical and theoretical methods, they share similar feature sets, including drug and cell-line features. Drug features include target genes [22,23], American Therapeutic Chemical Classification (ATC) codes [23,24], chemical structures [15,22,24,25], drug responses [26], and side effects and off side effects [25]. Transcriptome $[15,24,26]$ is the most popular among cell-line features, which also includes transcriptome-enriched pathways [23,25-27], gene ontology, and protein-protein interaction [24].

Several important unanswered biology questions remain regarding the prediction of drug-combination synergy. Are pathways more informative than individual genes in predicting drug synergies? Does gene essentiality, measured by CRISPR (clustered regular interspaced short palindromic repeats) or shRNA (short hairpin RNA), provide the same drug synergy prediction as gene expression? Do data regarding the expression or essentiality of drug target genes predict drug synergy? Most current computational biology approaches focus on optimizing prediction performance, but none were designed to answer these questions.

To investigate these questions, we applied our proposed systems pharmacology models, and statistical analyses. Firstly, we used drug combination synergy data from NCI ALMANAC, and employed logistic regression to test the statistical significance of gene and pathway features in that interaction. Gene expression, gene essentiality, KEGG pathways, and drug targets were used in the analysis. Then, we compared the pathways and genes, gene expression and essentiality, targets and non-targets in drug combination synergy prediction. At last, a validation using gene expression in 16 cell lines was performed. 


\section{Materials and Methods}

\subsection{Data Source}

\subsubsection{Data Regarding the Synergy of Drug Combinations}

We employed data accumulated in the NCI ALMANAC database regarding the synergy of drug combinations [13]. The ALMANAC project involved the systematic evaluation of the therapeutic activity of over 5000 pairs of 104 drugs approved by the FDA against a panel of 60 well-characterized human tumor cell lines (NCI-60). We employed a curated drug-target dataset to exclude drugs without targets [28,29] and finally included 2243 combinations of 69 drugs with targets in our analysis.

We evaluated the potential synergistic drug combinations utilizing ComboScores, as defined by Holbeck's group, to grade the level of presence or absence synergy of each drug in a given combination. Holbeck's group defined the Drug ComboScore [13] as a modification of Bliss independence. Let $Y^{A_{p} B_{q}}$ be the growth fraction for a cell line exposed to the pth concentration of Drug $A$ and the qth concentration of Drug $B$, defined as:

$$
Y^{A_{p} B_{q}}=100 * \frac{T_{1}^{A_{p} B_{q}}-T_{0}}{T_{1}^{0}-T_{0}}
$$

where $T_{0}$ is the time zero measurement, $T_{1}^{A_{p} B_{q}}$ is the endpoint measurement after 2 days under both $\operatorname{drugs} A$ and $B$, and $T_{1}^{0}$ is the endpoint measurement after 2 days for the control well. Define $Y^{A_{p}}, Y^{B_{q}}$ as the growth fractions when exposed to either Drug $A$ or Drug $B$ alone. The expected growth fraction for the combination is:

$$
Z^{A_{p} B_{q}}= \begin{cases}\min \left(Y^{A_{p}}, Y^{B_{q}}\right) & Y^{A_{p}} \leq 0 \text { or } Y^{B_{q}} \leq 0 \\ \frac{1}{100}\left(\widetilde{Y}^{A_{p}} * \widetilde{Y}^{B_{q}}\right) & \text { otherwise }\end{cases}
$$

where $\widetilde{Y}=\min (Y, 100)$ truncates the growth fraction at 100 . The final ComboScore for the cell line and the drug combination is the mean of the differences in expected versus observed growth fractions:

$$
Y^{A B}=\frac{1}{n} \sum_{p, q} Y^{A_{p} B_{q}}-Z^{A_{p} B_{q}}
$$

where $n$ is the number of the combinations for drugs $A$ and $B$ under different doses. The ComboScore ranges from -100 to 100 .

We calculated a binary synergy status $S^{A B}$ for drugs $A$ and $B$ based on a ComboScore with a threshold of 10 , above which a drug combination is considered synergistic.

$$
S^{A B}= \begin{cases}1 & Y^{A B}>10 \\ 0 & Y^{A B} \leq 10\end{cases}
$$

\subsubsection{Transcriptome Data}

We downloaded the baseline transcriptome data for the $60 \mathrm{NCI}$ cancer cell lines from NCI's CellMiner $^{\mathrm{TM}}$ database (Genomics and Pharmacology Facility, Developmental Therapeutics Branch, Center for Cancer Research, NCI) but excluded one cell line, MDA_N, for poor quality control [30]. This yielded 59 cell-line transcriptomes, which we analyzed using the Affymetrix ${ }^{\circledR}{ }^{\circledR}$ Human Genome U133 (HG-U133) Plus 2.0 platform [31]. We employed the R package "affy" to process CEL files, which made up the raw microarray data. MAS5.0 was used to normalize data, and the probes were matched to gene symbols. We calculated information regarding the presence, marginality, or absence of probe activity (PMA; present/margin/absent) in a sample for each probe and transformed the data to ascertain 
the transcriptome status. We considered a gene active when it demonstrated any probe activity and inactive when probe activity was absent. We used normalized gene expression in the analysis.

\subsubsection{Essentiality Data}

Gene essentiality was assessed by shRNA screening. We downloaded shRNA data from the Dependency Map (DepMap) portal of the Broad Institute [32], performed a genome-wide pooled loss-of-function screening among cancer cell lines across approximately $100 \mathrm{k}$ shRNAs, and applied the DEMETER2 (D2) analytical framework to this RNAi screening dataset [33]. We normalized the gene dependency score, D2, such that the median of the average score across cell lines was -1 for reference essential gene sets and zero for the control gene sets [34]. A threshold score of -0.5 was used to distinguish essential (below -0.5 ) and nonessential (above -0.5$)$ genes.

\subsubsection{Training and Validation Data}

Training data included 43 cancer cell lines with both base-line transcriptome and essentiality data as features. Validation samples were $16 \mathrm{NCI}$ cancer cell lines with only transcriptome data.

Pathway analysis utilized data regarding transcriptome, essentiality, and pathway features as enumerated by the Kyoto Encyclopedia of Genes and Genomes (KEGG) [35]. We employed the R package "KEGGREST" to download the genes from KEGG.

\subsection{Features}

We applied several rules to filter genes for analysis. Genes were excluded that were active (present) in fewer than $20 \%$ (8.6) of cell lines, demonstrated a coefficient of variance (CV) below 0.1 , or for the essential data, were not essential in all 43 cell lines. After filtering, 3024 gene expressions and 4381 gene essentialities remained, and their scores served as gene features

In constructing pathway features, we added drug target information into the calculation, utilizing target interactions reported by Feixiong Cheng and associates $[28,29]$ that we acquired from the DrugBank [36], Therapeutic Target (TTD) [37], and PharmGKB [38] databases. The following analysis included calculations of pathway features for 165 pathways with drug target genes. The model included two types of features. The first was based on drug targets in different cell lines, e.g., the numbers of active or essential genes in a cell line, numbers of all or common targets of drug combinations, and overlapping numbers of or proportions between active and essential genes and drug targets. The second feature type was based on cell lines and KEGG pathways, such as the numbers or proportions of active and essential genes in KEGG pathways for each cell line. Table 1 details these features. 
Table 1. Definitions of pathway features in the models.

\begin{tabular}{|c|c|c|c|}
\hline Data & Feature & Feature Description & Type \\
\hline \multirow{2}{*}{ Drug-combination targets } & $\mathrm{n}_{\mathrm{D} \_ \text {union_ab }}$ & Number of total drug targets for Drug A or Drug B & \\
\hline & $\mathrm{n}_{\mathrm{D} \_ \text {intersection_ab }}$ & Number of total drug targets for both Drug A and Drug B & \\
\hline KEGG pathways & $\mathrm{n}_{\mathrm{k}}$ & Number of genes in KEGG Pathway K & \\
\hline \multirow{2}{*}{ Cell lines } & $\mathrm{n}_{\text {cell_c_expression }}$ & Number of active genes in Cell Line C & 1 \\
\hline & $\mathrm{n}_{\text {cell_c essentiality }}$ & Number of essential genes in Cell Line C & 1 \\
\hline \multirow{3}{*}{$\begin{array}{l}\text { Drug-combination targets in cell lines } \\
\text { based on gene expression }\end{array}$} & $\mathrm{n}_{\text {cell_c_expression_D_union_ab }}$ & $\begin{array}{c}\text { Number of total drug targets for Drug A or Drug B that are } \\
\text { active in Cell Line C }\end{array}$ & \\
\hline & $\mathrm{n}_{\text {cell_c_expression_D_intersection_ab }}$ & $\begin{array}{c}\text { Number of total drug targets for both Drug A and Drug B that } \\
\text { are active in Cell Line C }\end{array}$ & 1 \\
\hline & $\mathrm{n}_{\text {cell_c_expression_D_union_ab/ }} \mathrm{n}_{\text {cell_c_expression }}$ & $\begin{array}{c}\text { Ratio of the number of active drug targets for Drug A or Drug B } \\
\text { to all active genes in Cell Line C }\end{array}$ & \\
\hline \multirow{5}{*}{$\begin{array}{l}\text { Drug-combination targets and cell lines } \\
\text { based on gene essentiality }\end{array}$} & 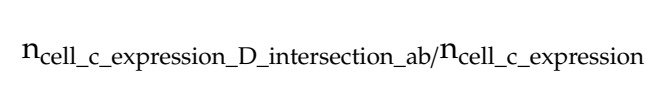 & $\begin{array}{l}\text { Ratio of the number of active drug targets for Drug A and Drug } \\
\text { B to all active genes in Cell Line C }\end{array}$ & \\
\hline & $\mathrm{n}_{\text {cell_c_essentiality_D_union_ab }}$ & $\begin{array}{c}\text { Number of total drug targets for Drug A or Drug B that are } \\
\text { essential in Cell Line C }\end{array}$ & \\
\hline & $\mathrm{n}_{\text {cell_c_essentiality_D_intersection_ab }}$ & $\begin{array}{c}\text { Number of total drug targets for both Drug A and Drug B that } \\
\text { are essential in Cell Line C }\end{array}$ & 1 \\
\hline & $\mathrm{n}_{\text {cell_c_essentiality_D_union_ab/ }} \mathrm{n}_{\text {cell_c_essentiality }}$ & $\begin{array}{l}\text { Ratio of the number of essential drug targets for Drug A or } \\
\text { Drug B relative to all essential genes in Cell Line C }\end{array}$ & \\
\hline & 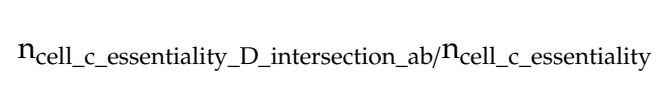 & $\begin{array}{c}\text { Ratio of the number of essential drug targets for Drug A and } \\
\text { Drug B relative to all essential genes in Cell Line C }\end{array}$ & \\
\hline $\begin{array}{l}\text { KEGG pathways and cell lines based on } \\
\text { gene expression }\end{array}$ & $\begin{array}{c}\mathrm{n}_{\text {cell_cc_expression_kegg_k }} \\
\mathrm{n}_{\text {cell_c_expression_kegg_k } /} \mathrm{n}_{\text {cell_c_expression }}\end{array}$ & $\begin{array}{c}\text { Number of active genes in KEGG Pathway K for Cell Line C } \\
\text { Ratio of the number of active genes in KEGG Pathway K } \\
\text { relative to all active genes in Cell Line C }\end{array}$ & 2 \\
\hline $\begin{array}{l}\text { KEGG pathways and cell lines Based on } \\
\text { gene essentiality }\end{array}$ & $\begin{array}{c}\mathrm{n}_{\text {cell_c_essentiality_kegg_k }} \\
\mathrm{n}_{\text {cell_c_essentiality_kegg_k} /} \mathrm{n}_{\text {cell_c_essentiality }}\end{array}$ & $\begin{array}{c}\text { Number of essential genes in KEGG Pathway K for Cell Line C } \\
\text { Ratio of the number of essential genes in KEGG Pathway K to } \\
\text { all essential genes in Cell Line C }\end{array}$ & 2 \\
\hline
\end{tabular}

KEGG, Kyoto Encyclopedia of Genes and Genomes. 


\subsection{Logistic Regression Models in Selecting Features for Drug-Synergy Prediction}

In gene analysis, we built a logistic regression model using the score of expression or essentiality for each gene as the given feature.

In analyzing and selecting features to predict drug synergy in pathway analysis, we trained logistic models with different types of features and performed three groups of analysis. Pathway Analysis 1 utilized the first type of feature only, Pathway Analysis 2, the second type only, and Pathway Analysis 3, all features.

For each gene or pathway, we chose the minimum $p$-value among all the drug combinations to represent the overall $p$-value for the given gene or pathway. In the gene-level modes, we set a genome-wide threshold for Bonferroni correction of multiple comparisons $10^{-5}$ based on expression of 3024 genes and essentiality of $4381\left(10^{-5} \approx 0.05 / 3024 \approx 0.05 / 4381\right)$. In the pathway analysis, we set the Bonferroni correction threshold $2.66 * 10^{-5}$ based on 165 pathways and 114 drug combinations $\left(2.66 * 10^{-5}=\frac{0.05}{165 * 114}\right)$.

To assess and compare the models, we calculated multiple levels of the false discovery rate (FDR). For a given $p$-value threshold, FDR is calculated as the ratio of the number of expected to the number of observed significant results.

\subsection{Model Training and Validation}

Training and validation focused on the transcriptome features and their related pathway features in predicting drug-combination synergy. Unfortunately, no additional data were available to validate gene essentiality features and their pathway features.

\section{Results}

It is very challenging to construct a model to predict the synergy of drug combinations that show synergy in only a very few cell lines, so we examined 114 drug combinations that showed synergy in at least five cell lines.

\subsection{In Overall Trend Analysis, Pathway Features Showed Stronger Statistical Correlation Evidence Than Gene} Features with Drug-Combination Synergy Scores

When we used the same $p$-value thresholds, $0.01,0.001,0.0001$, the FDRs of gene expression and essentiality features varied from 0.19 to 0.60 , and gene expression features were somewhat better predictors of drug synergy than essentiality features with lower FDRs (Figure 1a,b). However, pathway analysis using the same $p$-value thresholds demonstrated uniformly lower FDRs of pathway than gene features, varying between 0.01 and 0.24 . Gene expressions and essentialities did not differ among pathways. In particular, we observed lower FDRs of the pathway features that integrated data of both expression and essentiality than those based on either expression or essentiality alone (Table 2, Figure 1c,d). 
a

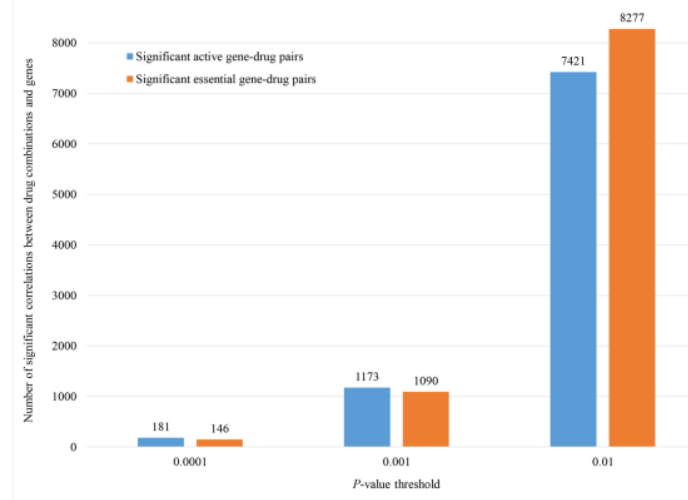

c

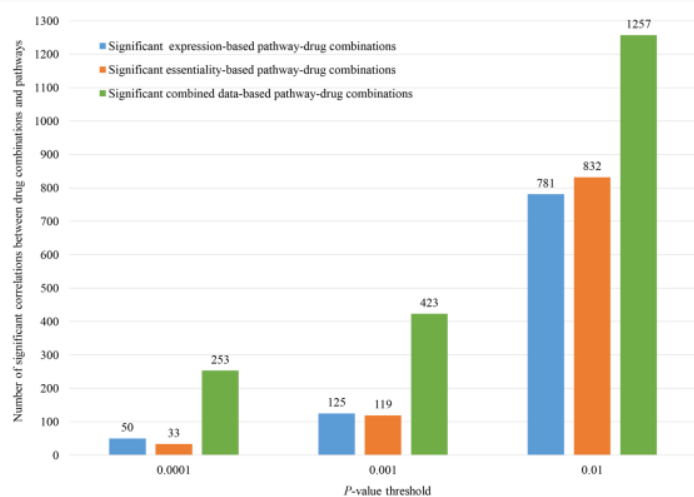

b

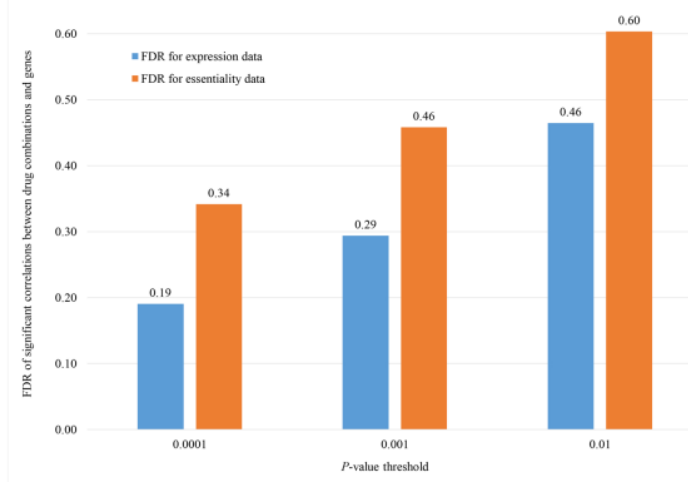

d

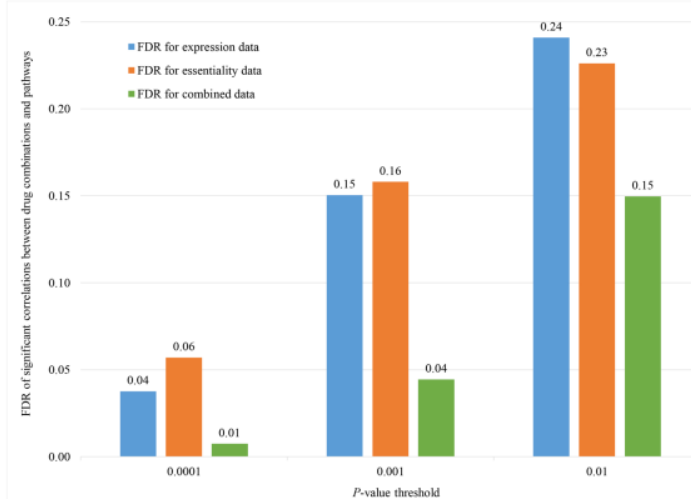

Figure 1. Comparison of significant correlations between drug pairs and genes and drug pairs and pathways under different thresholds. (a,b) Number and false discovery rate (FDR) of significant correlation between drug pairs and genes. (c,d) Number and FDR of significant correlation between drug pairs and pathways. 
Table 2. Results of pathway analysis.

\begin{tabular}{|c|c|c|c|c|c|c|c|c|c|c|c|c|c|}
\hline \multirow{2}{*}{\multicolumn{2}{|c|}{ Group }} & \multicolumn{4}{|c|}{ Gene Expression } & \multicolumn{4}{|c|}{ Gene Essentiality } & \multicolumn{4}{|c|}{ Combined Expression and Essentiality } \\
\hline & & Threshold & $\begin{array}{l}\text { Number } \\
\text { Observed }\end{array}$ & $\begin{array}{l}\text { Number } \\
\text { Expected }\end{array}$ & FDR & Threshold & $\begin{array}{l}\text { Number } \\
\text { Observed }\end{array}$ & $\begin{array}{l}\text { Number } \\
\text { Expected }\end{array}$ & FDR & Threshold & $\begin{array}{l}\text { Number } \\
\text { Observed }\end{array}$ & $\begin{array}{l}\text { Number } \\
\text { Expected }\end{array}$ & FDR \\
\hline \multirow{3}{*}{\multicolumn{2}{|c|}{1}} & 0.0001 & 0 & 0.01 & NA & 0.0001 & 1 & 0.01 & 0.01 & 0.0001 & 1 & 0.01 & 0.01 \\
\hline & & 0.001 & 0 & 0.11 & NA & 0.001 & 1 & 0.11 & 0.11 & 0.001 & 1 & 0.11 & 0.11 \\
\hline & & 0.01 & 4 & 1.14 & 0.29 & 0.01 & 2 & 1.14 & 0.57 & 0.01 & 7 & 1.14 & 0.16 \\
\hline \multirow{4}{*}{\multicolumn{2}{|c|}{$\mathrm{DD}^{*}$}} & 0.0001 & 7 & 0.01 & $1.43 \times 10^{-3}$ & 0.0001 & 2 & 0.01 & 0.005 & 0.0001 & 11 & 0.01 & $9.09 \times 10^{-4}$ \\
\hline & & 0.001 & 25 & 0.11 & $4.4 \times 10^{-3}$ & 0.001 & 15 & 0.11 & $7.33 \times 10^{-3}$ & 0.001 & 35 & 0.11 & $3.14 \times 10^{-3}$ \\
\hline & & 0.01 & 72 & 1.14 & 0.016 & 0.01 & 77 & 1.14 & 0.015 & 0.01 & 85 & 1.14 & 0.013 \\
\hline & & 0.0001 & 8 & 1.88 & 0.24 & 0.0001 & 3 & 1.88 & 0.63 & 0.0001 & 16 & 1.88 & 0.12 \\
\hline \multirow{3}{*}{\multicolumn{2}{|c|}{$\mathrm{DDP} \#$}} & 0.001 & 43 & 18.81 & 0.44 & 0.001 & 25 & 18.81 & 0.75 & 0.001 & 78 & 18.81 & 0.24 \\
\hline & & 0.01 & 443 & 188.1 & 0.42 & 0.01 & 311 & 188.1 & 0.60 & 0.01 & 519 & 188.1 & 0.36 \\
\hline & & 0.0001 & 23 & 0.01 & $4.35 \times 10^{-4}$ & 0.0001 & 13 & 0.01 & $7.69 \times 10^{-4}$ & 0.0001 & 37 & 0.01 & $2.72 \times 10^{-4}$ \\
\hline \multirow{3}{*}{\multicolumn{2}{|c|}{$\mathrm{DD}^{*}$}} & 0.001 & 36 & 0.11 & $3.06 \times 10^{-3}$ & 0.001 & 26 & 0.11 & $4.23 \times 10^{-3}$ & 0.001 & 62 & 0.11 & $1.77 \times 10^{-3}$ \\
\hline & & 0.01 & 86 & 1.14 & 0.013 & 0.01 & 61 & 1.14 & 0.019 & 0.01 & 98 & 1.14 & 0.012 \\
\hline & & 0.0001 & 50 & 1.88 & 0.038 & 0.0001 & 33 & 1.88 & 0.057 & 0.0001 & 253 & 1.88 & $7.43 \times 10^{-3}$ \\
\hline \multirow{2}{*}{\multicolumn{2}{|c|}{$\mathrm{DDP} \#$}} & 0.001 & 125 & 18.81 & 0.15 & 0.001 & 119 & 18.81 & 0.16 & 0.001 & 423 & 18.81 & 0.044 \\
\hline & & 0.01 & 781 & 188.1 & 0.24 & 0.01 & 832 & 188.1 & 0.23 & 0.01 & 1257 & 188.1 & 0.15 \\
\hline
\end{tabular}

$\mathrm{DD}^{*}$, drug-pair model; the minimum $p$-value among all pathways was set to be the overall $p$-value for a drug pair. DDP \#, drug pair-pathway model; each $p$-value for every drug combination-pathway model was evaluated. FDR, false discovery rate. NA, not applicable. 
3.2. Genome-Wide Association Analyses Revealed Significant Associations of Genes and Pathways with Scores of Drug Synergy

Gene analyses demonstrated significant association of 30 expressed genes and 16 essential genes with drug synergy scores under the Bonferroni threshold, but they shared no common gene. Supplementary Table S1 delineates these genes, and they are marked in Figure 2. In these figures, the $\mathrm{X}$ axis represents the genes arranged from chromosomes, and the $\mathrm{Y}$ axis, the overall $p$-value $(-\log 10)$.
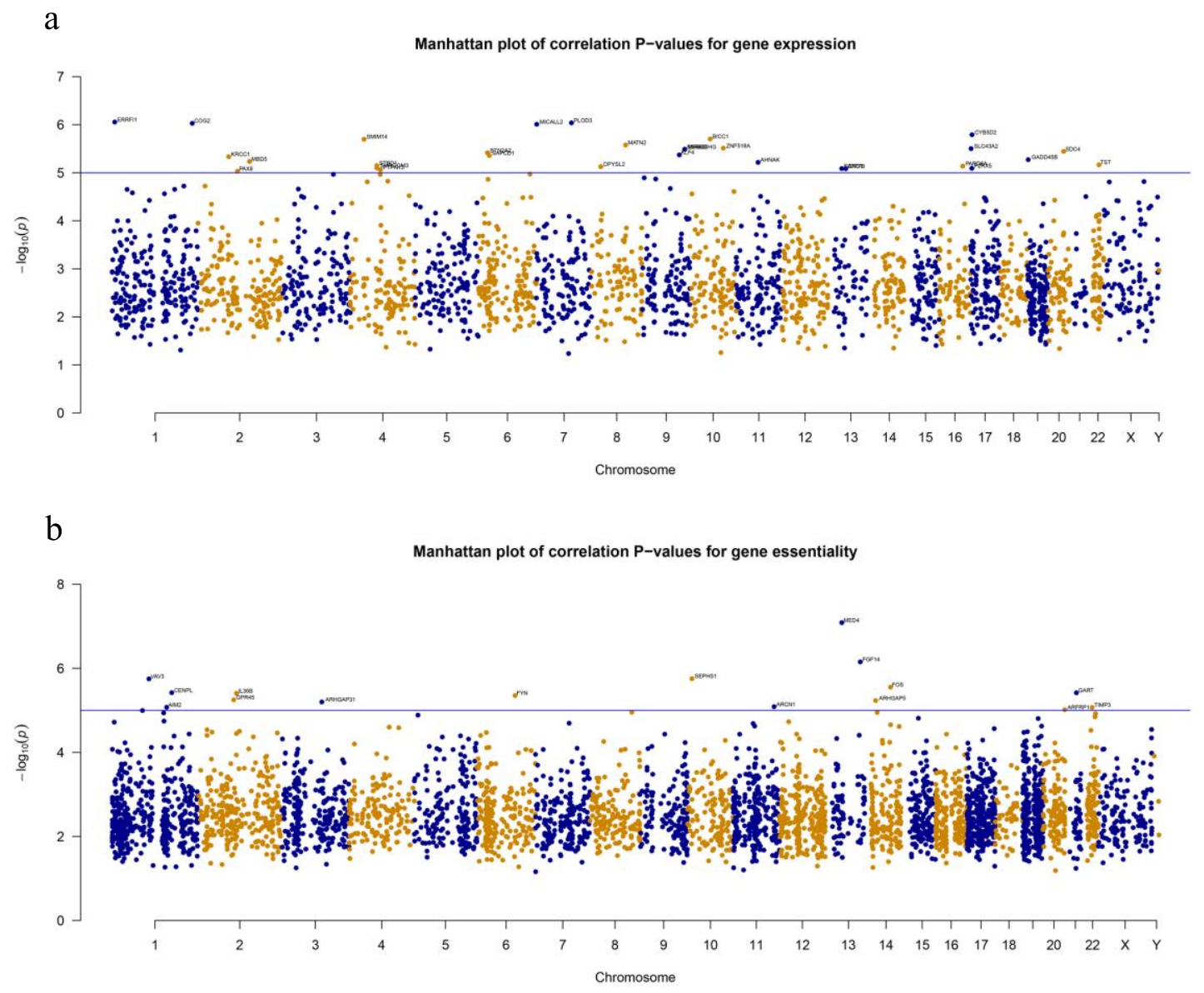

Figure 2. Manhattan plots of correlation $p$-values. (a) Gene expression data, (b) gene essentiality data. In these figures, the $\mathrm{X}$ axis represents the genes, and the $\mathrm{Y}$ axis represents the overall $p$-value $(-\log 10)$.

For drug-synergy scores under the Bonferroni threshold, Pathway Analysis 3 demonstrated significant association of four pathways using gene expression (PI3K-AKT and AMPK signaling pathways, antigen processing and presentation, and pancreatic secretion), two using essentiality (aldosterone-regulated sodium reabsorption and progesterone-mediated oocyte maturation), and five using the combined data (cellular senescence, alanine, aspartate and glutamate metabolism, insulin secretion, vascular smooth muscle contraction, and gap junction). However, there was no common pathway among them. Figure 3 shows the distribution. 
a

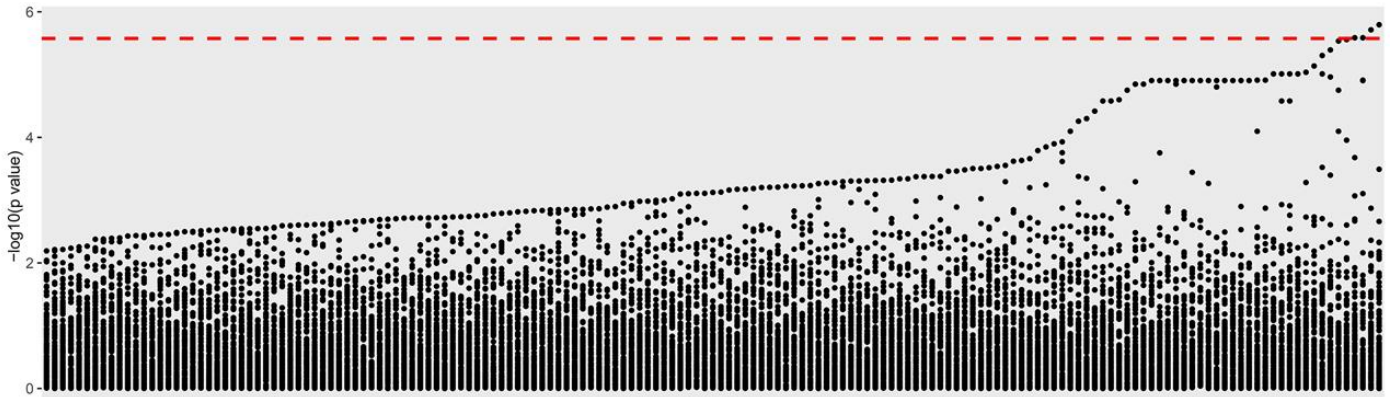

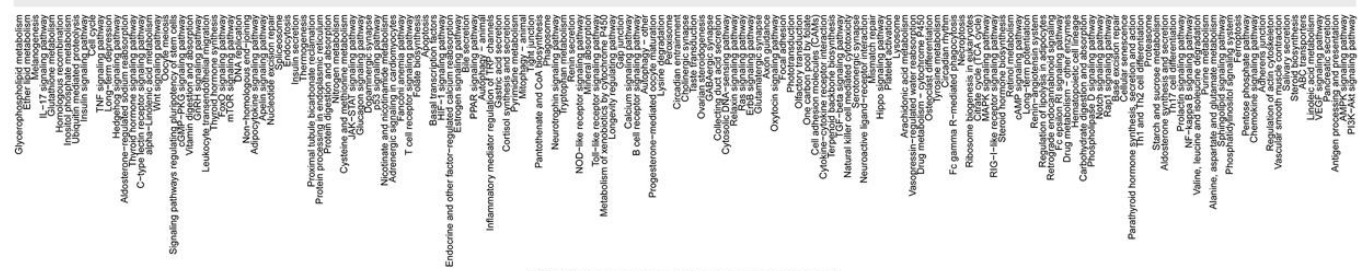

KEGG pathways based on gene expression

b
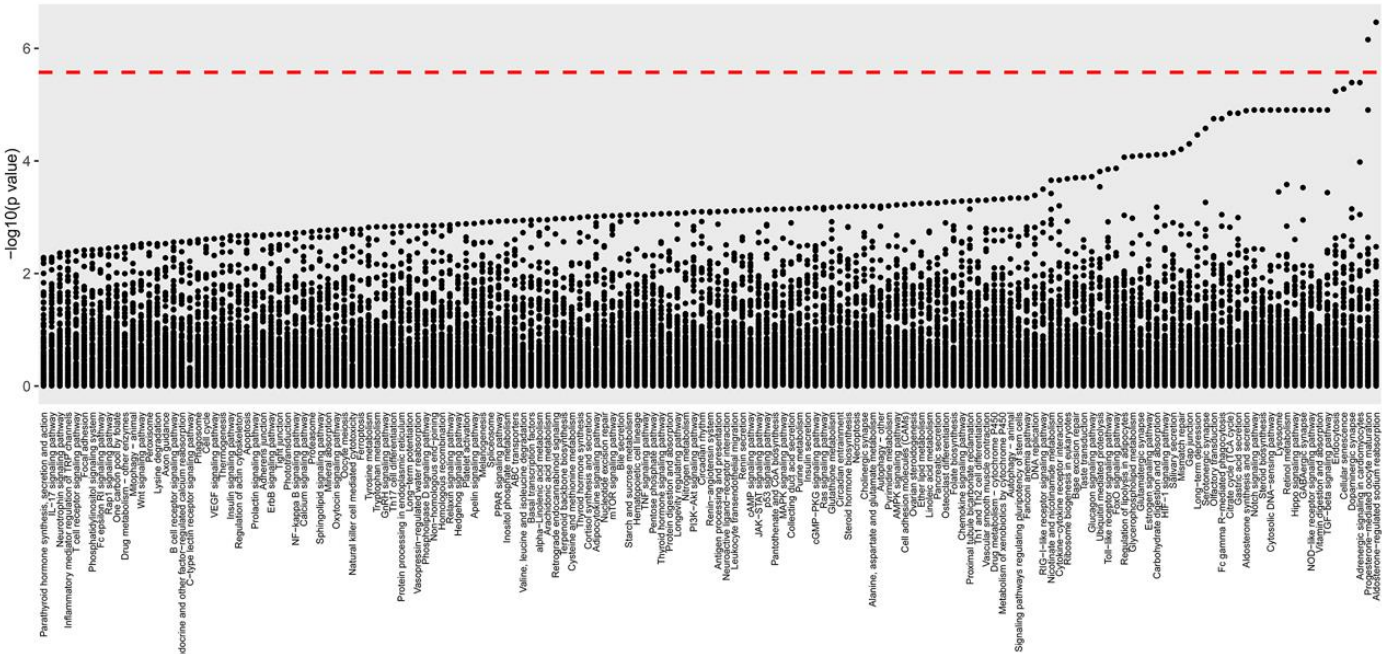

KEGG pathways based on gene essentiality

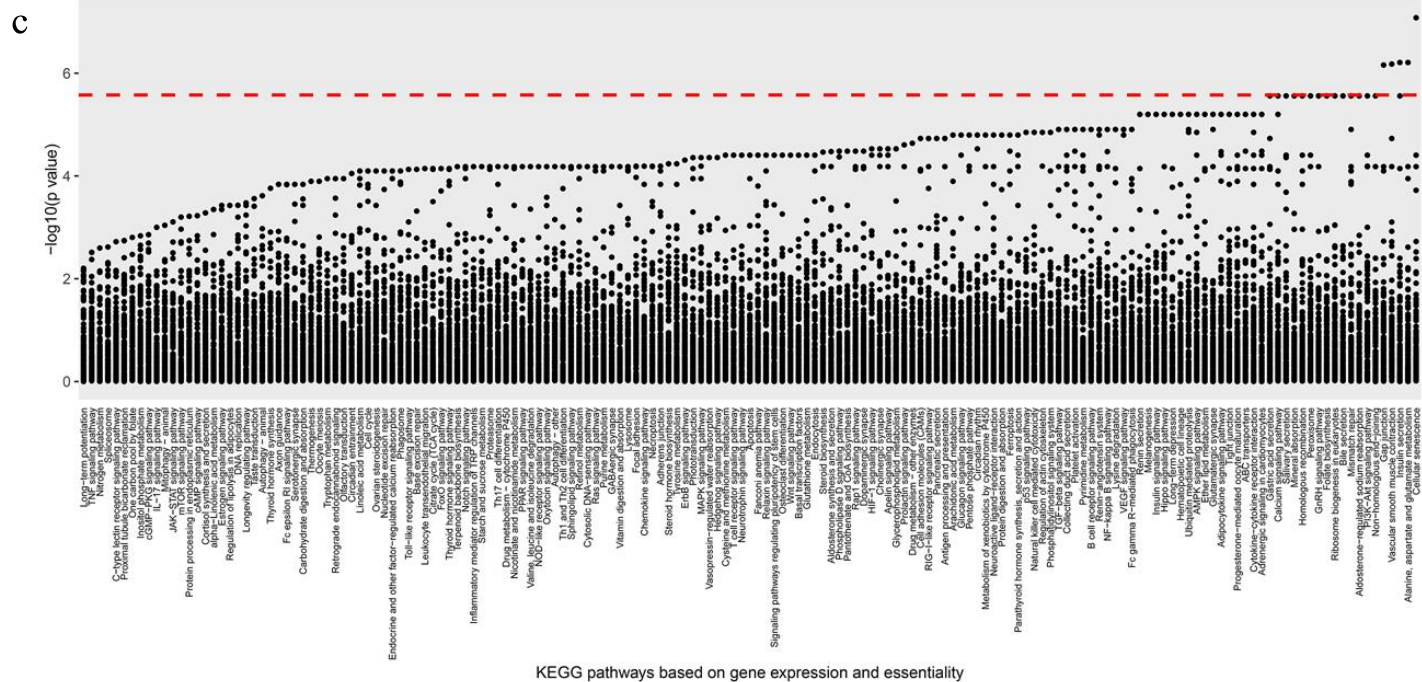

Figure 3. Scatter plots of correlation $p$-values in Pathway Analysis 3. (a) Gene expression data, (b) gene essentiality data, (c) combined data. In these figures, the $\mathrm{X}$ axis represents the pathways, and the $\mathrm{Y}$ axis represents the overall $p$-value $(-\log 10)$. 
Under a genome-wide adjusted significance level, these association analyses revealed significant correlation between drug-synergy scores and several genes and pathways. However, the different genes and pathways between expression and essentiality indicated different mechanisms of gene expression and essentiality at work in the synergistic activity of the drug combinations.

\subsection{Overlap Was Limited between Significant Gene Expressions and Essentialities in Predicting Drug Synergy}

Gene analysis revealed 473 common genes among expression (3024 genes) and essentiality (4381 genes) datasets. Under an overall $p$-value threshold of 0.001 , drug combinations correlated significantly with expression in 34 genes and essentiality in 20, with only one gene showing overlap in expression and essentiality (Figure $4 a$ ).

a
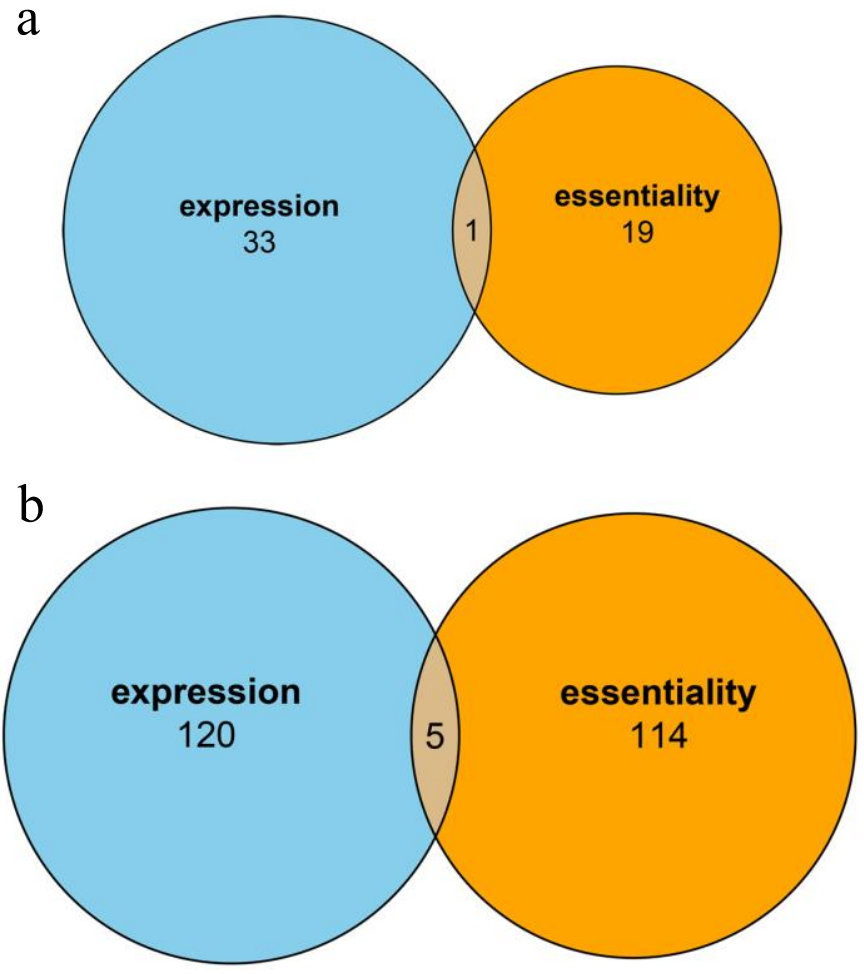

Figure 4. Venn plots illustrating results between gene expression and essentiality. (a) Number of significant drug combination-gene relationships using gene expression and essentiality, (b) number of significant drug combination-pathway relationships using gene expression and essentiality.

Under an overall $p$-value threshold of 0.001, Pathway Analysis 3 demonstrated significant correlation of drug combinations and expression in 125 genes and essentiality in 119, with only five genes showing overlap in expression and essentiality (Figure $4 b$ ).

Both the gene and pathway analyses revealed quite different information regarding gene expression and essentiality for predicting drug-combination synergy.

\subsection{No Statistically Significant Evidence Supported Relationship between Target and Non-Target Genes and Pathways in the Prediction of Drug Synergy}

For each drug combination, we separated gene features into target and non-target features, including expression and essentiality features, and we further differentiated whether target genes were in a pathway, including pathways defined by gene expressions and essentialities. Comparison between the target and non-target groups showed no significant differences between genes (Figure $5 a, b$ ) or pathways (Figure $5 c, d$ ). In the violin plot, there is a box in each violin. The lines in the box are first quartile $\left(\mathrm{Q}_{1}\right)$, medium $\left(\mathrm{Q}_{2}\right)$, and third quartile $\left(\mathrm{Q}_{3}\right)$. The curves of violin plots also show the probability density of the data at different values, smoothed by a kernel density estimator. 
a

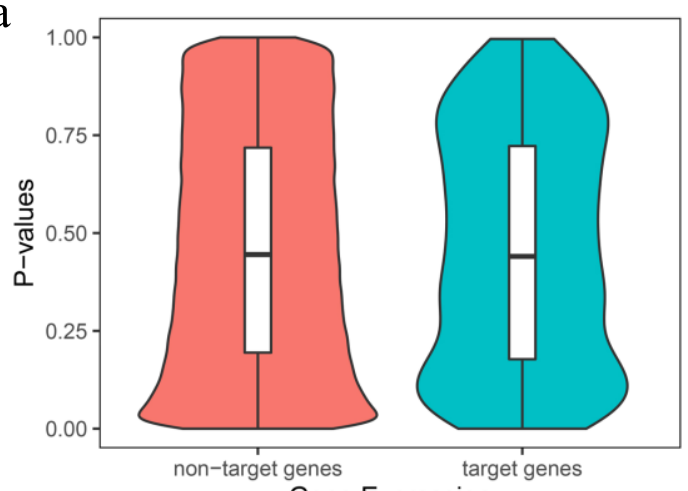

Gene Expression

C

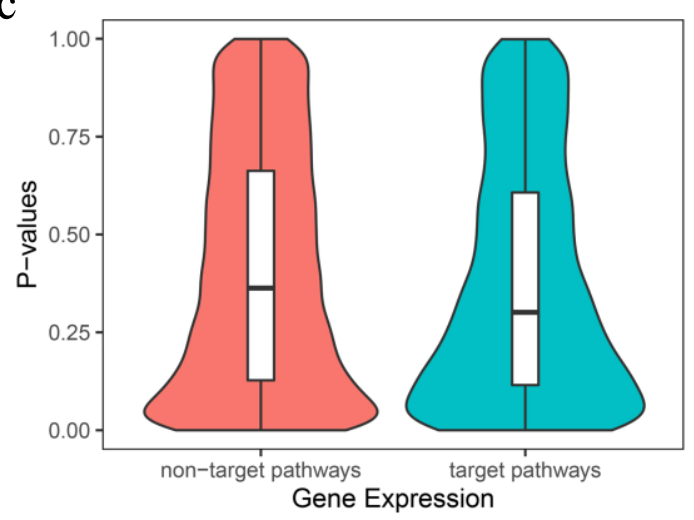

$\mathrm{b}$

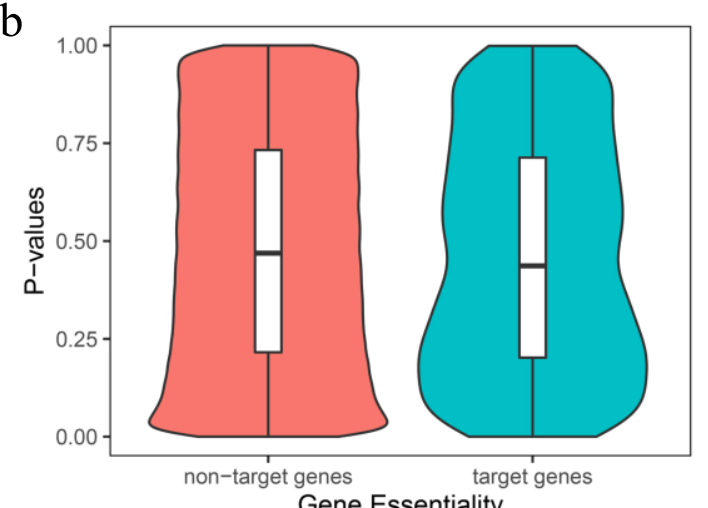

d

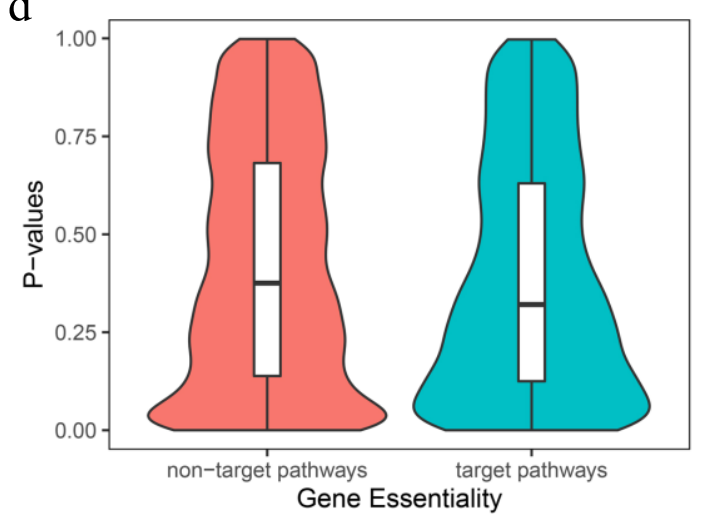

Figure 5. Violin plots of $p$-values for target and non-target genes (a,b) and pathways (c,d) using (a) gene expression, (b) gene essentiality, (c) gene expression, and (d) gene essentiality.

\subsection{Feature Comparison in Pathway Analysis}

Pathway Analysis 1 included information regarding drug-combination targets and gene expression and essentiality based on cell-line information and did not include pathway information. For each drug combination, a separate model was constructed for gene expression and for essentiality. Pathway Analyses 2 and 3 included pathway information, so for each drug combination and pathway, a separate model was trained for gene expression and for essentiality. For each drug combination, we set the minimum $p$-value among all pathways as the overall $p$-value for the drug combination to allow comparison with the model constructed based on the first group of features. Table 2 shows the FDRs using different thresholds.

We first compared the drug combination level results. In Pathway Analysis 1, of 114 drug combinations, zero (expression data), one (essentiality data), and one (combined data) FDR = (NA, 0.11 and 0.11 ) can be properly predicted under a $p$-value threshold of 0.001 .

In Pathway Analysis 2, 25 (expression data), 15 (essentiality data), and 35 (combined data) FDR = $\left(4.4 \times 10^{-3}, 7.33 \times 10^{-3}\right.$ and $\left.3.14 \times 10^{-3}\right)$ can be properly predicted.

In Pathway Analysis 3, 36 (expression data), 26 (essentiality data), and 62 (combined data) FDR = $\left(3.06 \times 10^{-3}, 4.23 \times 10^{-3}\right.$ and $\left.1.77 \times 10^{-3}\right)$ can be properly predicted. Obviously, pathway features were more informative than the basic cell-line information, and integrated features in Pathway Analysis 3 performed best.

We then compared the results regarding drug combinations and pathway level between Pathway Analyses 2 and 3. In Pathway Analysis 2, 43 (expression data), 25 (essentiality data), and 78 (combined data) of drug combination-pathways FDR $=(0.44,0.75$ and 0.24$)$ can be properly predicted under a $p$-value threshold of 0.001. In Pathway Analysis 3, the numbers were 125 (expression data), 119 (essentiality data), and 423 (combined data) $F D R=(0.15,0.16$ and 0.044$)$. The integration of information regarding pathways and cell lines in Pathway Analysis 3 was more informative than the pathway 
information alone in Pathway Analysis 2. Results were similar using $p$-value thresholds of 0.01 and 0.0001 (Table 2).

FDR results were similar or slightly better based on expression rather than essentiality and were best when expression and essentiality were combined. Subsequent analysis of the correlation between expression and essentiality to investigate the amount of information they shared yielded: Pearson (Spearman) correlation coefficients of $p$-values of 0.3105 for expression and 0.3074 for essentiality in Pathway Analysis 1; 0.0430 for expression and 0.0453 for essentiality in Pathway Analysis 2; and 0.5578 for expression and 0.5766 for essentiality in Pathway Analysis 3 (Figure 6). These values reflected little common information between gene expression and essentiality if they were used separately (Pathway Analysis 2).
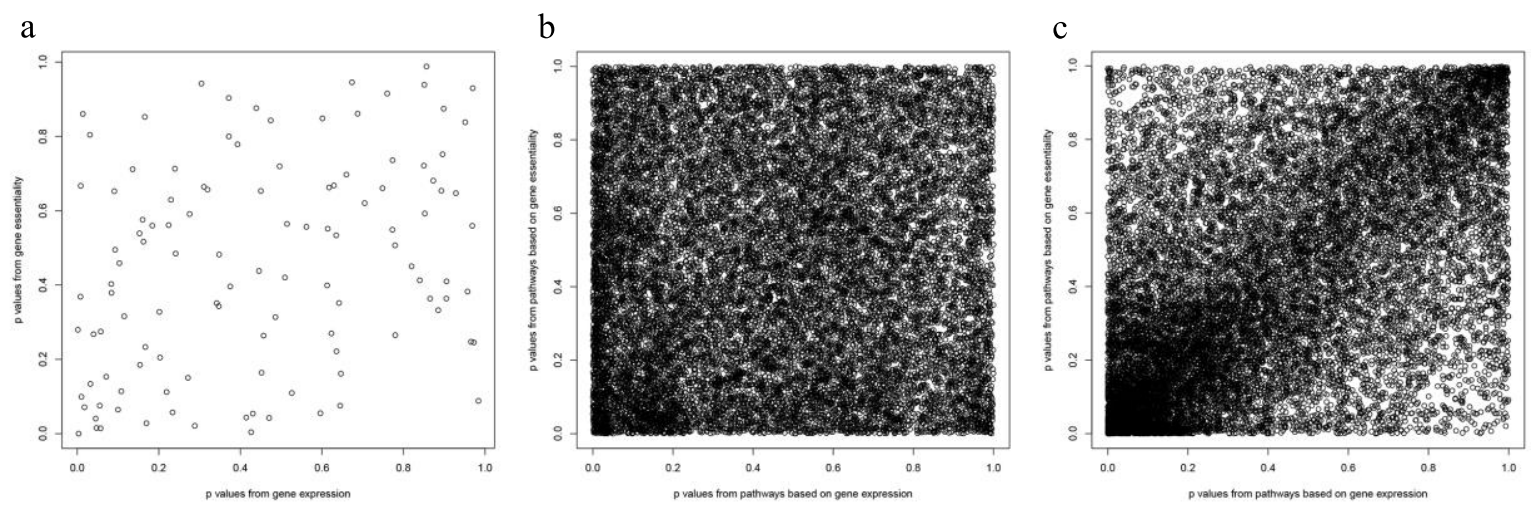

Figure 6. Scatter plot of the $p$-values from gene expression and essentiality. The more points in the main diagonal, the more correlation between the 2 groups. (a-c) Feature groups $1-3$.

\subsection{Model Validation}

For validation, we selected the two most significant correlations of drug-combination pathways using gene expression data in Feature Group 3. The signaling pathways were PI3K-Akt for the combination of drugs Nelarabine and Exemestane and AMPK for the combination of Docetaxel and Vemurafenib. PI3K-Akt pathway is an intracellular signal transduction pathway that promotes metabolism, proliferation, cell survival, growth and angiogenesis in response to extracellular signals. This is mediated through serine and/or threonine phosphorylation of a range of downstream substrates. Key proteins involved are phosphatidylinositol 3-kinase (PI3K) and Akt/Protein Kinase B [39]. Nelarabine is a chemotherapy drug used in T-cell acute lymphoblastic leukemia. Its target gene is POLA1. Exemestane is a member of the class of antiestrogens known as aromatase inhibitors, which is used to treat breast cancer. Its target genes are NFE2L2 and AR. One of the central regulators of cellular and organismal metabolism in eukaryotes is AMP-activated protein kinase (AMPK), which is activated when intracellular ATP production decreases. AMPK has critical roles in regulating growth and reprogramming metabolism, and has recently been connected to cellular processes such as autophagy and cell polarity. The AMPK signaling pathway coordinates cell growth, autophagy, and metabolism [40]. Docetaxel is a chemotherapy medication used to treat a number of types of cancer, including breast cancer, head and neck cancer, stomach cancer, prostate cancer and non-small-cell lung cancer. Its target genes are MAP2, NR1I2, BCL2, TUBB1, MAPT, and MAP4. Vemurafenib is an inhibitor of the B-Raf enzyme for the treatment of late stage melanoma. Vemurafenib selectively binds to the ATP-binding site of BRAF (V600E) kinase and inhibits its activity, which may result in an inhibition of an over-activated MAPK signaling pathway downstream in BRAF (V600E) kinase-expressing tumor cells and a reduction in tumor cell proliferation. Its target genes are YES1, ARAF, BRAF, KDR and RAF1.

A non-parametric Wilcoxon test was used to compare the numbers of active genes in the pathways to classify the groups with and without synergy. The $p$-values are $0.03505,0.0656,0.007196$ and 0.01504 for groups a-d in Figure 7. In the 16 cell lines used for validation, only one reflected synergistic activity for Nelarabine and Exemestane and only two for Docetaxel and Vemurafenib. In this small and 
unbalanced data, especially the validation data, these small $p$-values of significance showed significant separation of these groups in both the training and validation datasets, even when only a single feature was considered (e.g., number of active genes in the pathway) (Figure 7). The results thus proved the efficiency of the pathway features used in the models.

a

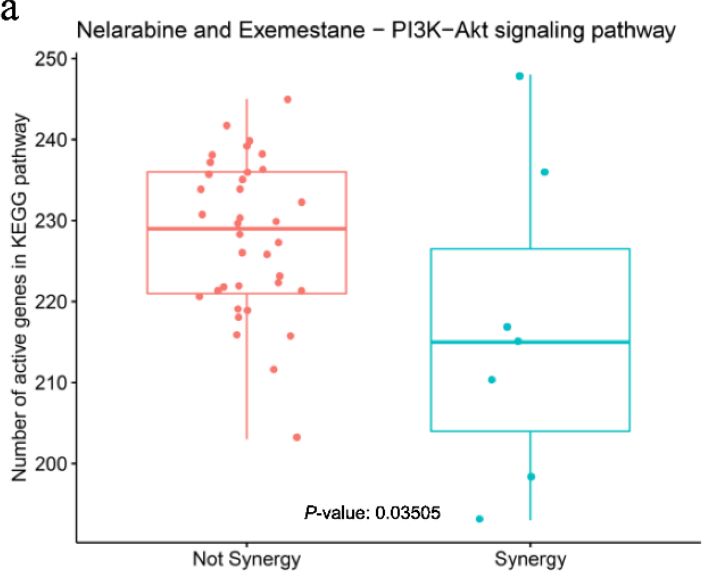

C

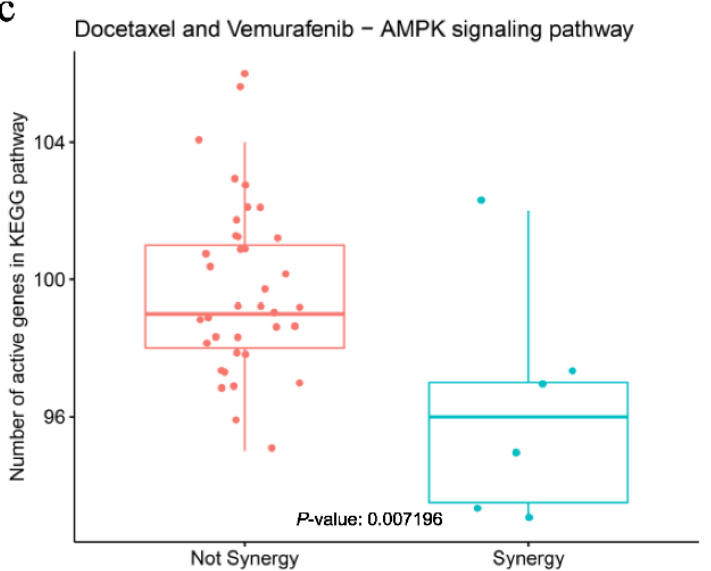

b

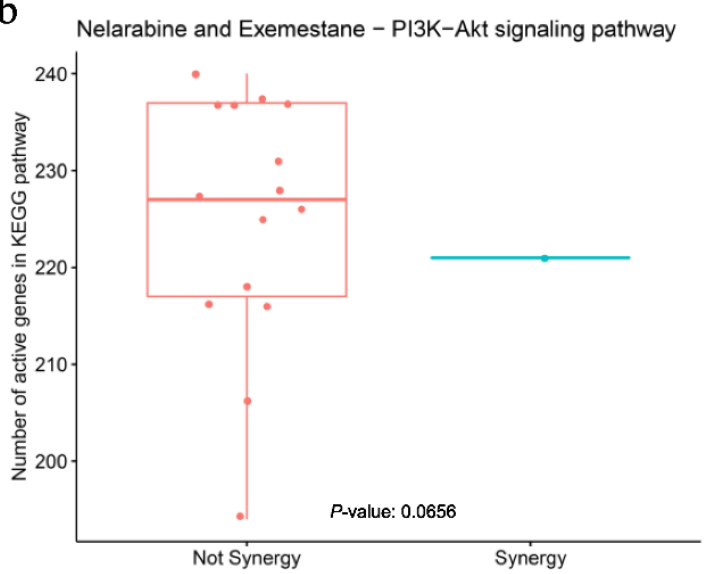

$\mathrm{d}$

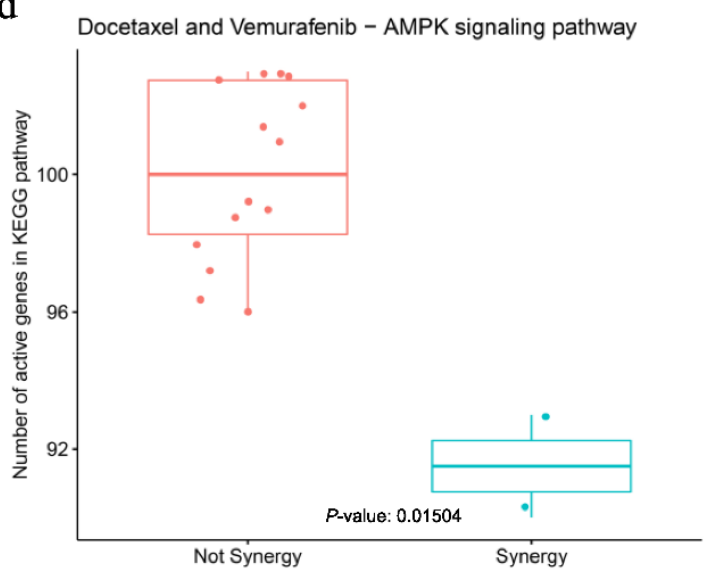

Figure 7. Box plot of the number of active genes in the KEGG pathway. The lines in the box are First quartile (Q1), Medium (Q2), and Third quartile (Q3). (a,c) training data; (b,d) validation data.

\section{Discussion}

In AstraZeneca's drug-combination prediction DREAM Challenge [14], the authors summarized and compared different models and features and observed better prediction performance when such data as KEGG information was added to the base-line model. Similarly, our model employed a pathway containing several genes rather than a single gene because we believed their regulatory relationship would hold some special function and make more biological meaning. More powerful prediction of drug synergy has been proven utilizing pathways rather than either expression or essentiality of a single gene. In this paper, in order to directly comparing genes and pathways, only 1 pathway was used in each model. The pathway interactions or crosstalk were not considered in the analysis.

There is no statistically significant evidence between target and non-target genes/pathways in the prediction of drug synergy. The possible reason is that the drug target information is still limited. Even several databases are used to acquire the drug targets, it is still limited and unbalanced. The number of target genes varies among drug types, such as monoclonal antibodies, Alkylating agents, Anthracyclines, and Mitotic inhibitors. Therefore, there are some biases on target-based pathways.

Currently, NCI ALMANAC is the largest drug combination synergy data. However, there are only 60 cell lines, and only 16 cell lines in the validation. This small sample size limited the power and robustness of our model. The significant correlations of AMPK signaling pathway and the drug 
combination Docetaxel and Vemurafenib were further validated in literature. The synergistic effect of this drug combination has been confirmed by in vitro study [41]. The targeted pathways were mapped based on the drug targets. Both of these two drugs target several pathways, and they target two common pathways (PI3K/Akt signaling pathway and MAPK signaling pathway), but none of them target AMPK signaling pathway directly. The interaction or crosstalk network between these pathways were further investigated. AMPK signaling is inhibited by hyperactive MAPK signaling in cancers, and the AMPK signaling can regulate MAPK signaling reversely [42]. There are crosstalk between the AMPK and PI3K/Akt pathways in breast cancer cells [43]. AMPK exerts dual effects on the PI3K/Akt pathway and mTOR pathway, stimulating PI3K/Akt and inhibiting mTOR/S6K [44,45]. AMPK Induces p53 pathway by Phosphorylating MDMX and inhibiting its activity [46] (Figure 8). There are lots of interactions or crosstalk between AMPK pathways and these directly targeted pathways, even it is not directly targeted. Therefore, it is not necessary that the most significant pathway is the directly targeted pathway, and a pathway which has interactions or crosstalk with the directly targeted pathways may also play important roles in drug synergy prediction.

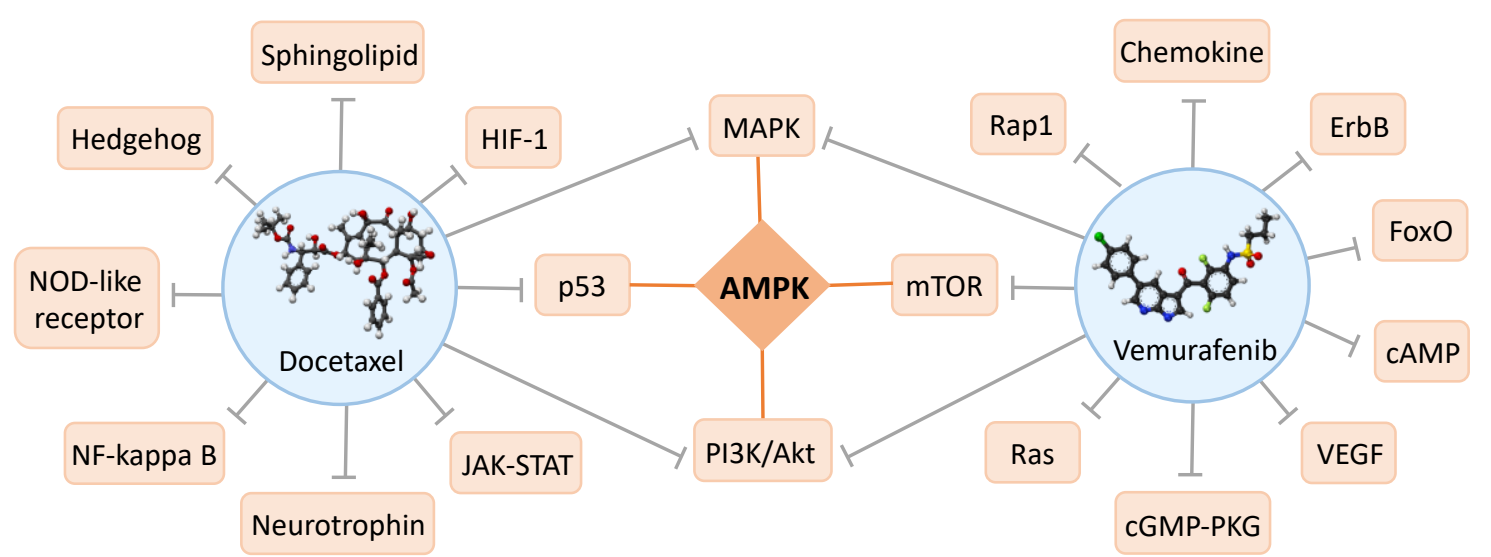

Figure 8. Docetaxel, Vemurafenib and targeted pathways.

\section{Conclusions}

This is the first study comparing gene expression and gene essentiality for drug synergy prediction. Gene expression and essentiality each reflect different functional mechanisms, and the consideration of one or the other has been effective in the prediction of drug synergy. Certainly, their combined consideration would enhance that prediction, and prediction should improve even further as more and more gene essentiality data become publicly available.

Supplementary Materials: The following are available online at http://www.mdpi.com/2079-7737/9/9/278/s1, Table S1: The overall $p$-values of genes based on gene expression and essentiality.

Author Contributions: Conceptualization, J.L. and L.L.; methodology, J.L. and L.L.; validation, X.W. and Z.Z.; data curation, Y.H.; writing—original draft preparation, J.L., Z.T., and K.F.; writing-review and editing, E.L., D.S., L.C., and L.L.; funding acquisition, L.L. All authors have read and agreed to the published version of the manuscript.

Funding: This research received no external funding.

Acknowledgments: The authors would like to thank Rosalyn A. Uhrig, M.A., for her editorial assistance in the preparation of our manuscript.

Conflicts of Interest: The authors declare no conflict of interest.

\section{References}

1. Van Allen, E.M.; Wagle, N.; Stojanov, P.; Perrin, D.L.; Cibulskis, K.; Marlow, S.; Jane-Valbuena, J.; Friedrich, D.C.; Kryukov, G.; Carter, S.L.; et al. Whole-exome sequencing and clinical interpretation 
of formalin-fixed, paraffin-embedded tumor samples to guide precision cancer medicine. Nat. Med. 2014, 20, 682-688. [CrossRef]

2. Frampton, G.M.; Fichtenholtz, A.; Otto, G.A.; Wang, K.; Downing, S.R.; He, J.; Schnall-Levin, M.; White, J.; Sanford, E.M.; An, P.; et al. Development and validation of a clinical cancer genomic profiling test based on massively parallel DNA sequencing. Nat. Biotechnol. 2013, 31, 1023-1031. [CrossRef]

3. Wagle, N.; Berger, M.F.; Davis, M.J.; Blumenstiel, B.; Defelice, M.; Pochanard, P.; Ducar, M.; Van Hummelen, P.; Macconaill, L.E.; Hahn, W.C.; et al. High-throughput detection of actionable genomic alterations in clinical tumor samples by targeted, massively parallel sequencing. Cancer Discov. 2012, 2, 82-93. [CrossRef]

4. Garraway, L.A.; Jänne, P.A. Circumventing cancer drug resistance in the era of personalized medicine. Cancer Discov. 2012, 2, 214-226. [CrossRef]

5. Dias-Santagata, D.; Akhavanfard, S.; David, S.S.; Vernovsky, K.; Kuhlmann, G.; Boisvert, S.L.; Stubbs, H.; McDermott, U.; Settleman, J.; Kwak, E.L.; et al. Rapid targeted mutational analysis of human tumours: A clinical platform to guide personalized cancer medicine. EMBO Mol. Med. 2010, 2, 146-158. [CrossRef]

6. Kerick, M.; Isau, M.; Timmermann, B.; Sültmann, H.; Herwig, R.; Krobitsch, S.; Schaefer, G.; Verdorfer, I.; Bartsch, G.; Klocker, H.; et al. Targeted high throughput sequencing in clinical cancer settings: Formaldehyde fixed-paraffin embedded (FFPE) tumor tissues, input amount and tumor heterogeneity. BMC Med. Genom. 2011, 4, 68. [CrossRef] [PubMed]

7. Roychowdhury, S.; Iyer, M.K.; Robinson, D.R.; Lonigro, R.J.; Wu, Y.M.; Cao, X.; Kalyana-Sundaram, S.; Sam, L.; Balbin, O.A.; Quist, M.J.; et al. Personalized oncology through integrative high-throughput sequencing: A pilot study. Sci. Transl. Med. 2011, 3, 111ra121. [CrossRef] [PubMed]

8. Jones, S.; Anagnostou, V.; Lytle, K.; Parpart-Li, S.; Nesselbush, M.; Riley, D.R.; Shukla, M.; Chesnick, B.; Kadan, M.; Papp, E.; et al. Personalized genomic analyses for cancer mutation discovery and interpretation. Sci. Transl. Med. 2015, 7, 283ra53. [CrossRef]

9. Carter, J.; Cheng, L.; Zucker, J.; Marshall, M.; Pollok, K.; Murray, M.; Li, L.; Renbarger, J. Use of Precision Medicine Molecular Profiling of Baseline Tumor Specimen May Not Benefit Outcomes in Children with Relapsed or Refractory Pediatric Sarcomas. Clin. Pharmacol. Ther. 2017, 101, 328-330. [CrossRef] [PubMed]

10. Ding, P.; Yin, R.; Luo, J.; Kwoh, C.K. Ensemble Prediction of Synergistic Drug Combinations Incorporating Biological, Chemical, Pharmacological, and Network Knowledge. IEEE J. Biomed. Health Inform. 2019, 23, 1336-1345. [CrossRef]

11. O'Neil, J.; Benita, Y.; Feldman, I.; Chenard, M.; Roberts, B.; Liu, Y.; Li, J.; Kral, A.; Lejnine, S.; Loboda, A.; et al. An Unbiased Oncology Compound Screen to Identify Novel Combination Strategies. Mol. Cancer Ther. 2016, 15, 1155-1162. [CrossRef] [PubMed]

12. Al-Lazikani, B.; Banerji, U.; Workman, P. Combinatorial drug therapy for cancer in the post-genomic era. Nat. Biotechnol. 2012, 30, 679-692. [CrossRef] [PubMed]

13. Holbeck, S.L.; Camalier, R.; Crowell, J.A.; Govindharajulu, J.P.; Hollingshead, M.; Anderson, L.W.; Polley, E.; Rubinstein, L.; Srivastava, A.; Wilsker, D.; et al. The National Cancer Institute ALMANAC: A Comprehensive Screening Resource for the Detection of Anticancer Drug Pairs with Enhanced Therapeutic Activity. Cancer Res. 2017, 77, 3564-3576. [CrossRef] [PubMed]

14. Menden, M.P.; Wang, D.; Mason, M.J.; Szalai, B.; Bulusu, K.C.; Guan, Y.; Yu, T.; Kang, J.; Jeon, M.; Wolfinger, R.; et al. Community assessment to advance computational prediction of cancer drug combinations in a pharmacogenomic screen. Nat. Commun. 2019, 10, 2674. [CrossRef] [PubMed]

15. Preuer, K.; Lewis, R.P.I.; Hochreiter, S.; Bender, A.; Bulusu, K.C.; Klambauer, G. DeepSynergy: Predicting anti-cancer drug synergy with Deep Learning. Bioinformatics 2018, 34, 1538-1546. [CrossRef]

16. Sidorov, P.; Naulaerts, S.; Ariey-Bonnet, J.; Pasquier, E.; Ballester, P.J. Predicting Synergism of Cancer Drug Combinations Using NCI-ALMANAC Data. Front. Chem. 2019, 7, 509. [CrossRef]

17. Jiang, P.; Huang, S.; Fu, Z.; Sun, Z.; Lakowski, T.M.; Hu, P. Deep graph embedding for prioritizing synergistic anticancer drug combinations. Comput. Struct. Biotechnol. J. 2020, 18, 427-438. [CrossRef]

18. Huang, L.; Brunell, D.; Stephan, C.; Mancuso, J.; Yu, X.; He, B.; Thompson, T.C.; Zinner, R.; Kim, J.; Davies, P.; et al. Driver network as a biomarker: Systematic integration and network modeling of multi-omics data to derive driver signaling pathways for drug combination prediction. Bioinformatics 2019, 35, 3709-3717. [CrossRef]

19. Li, H.; Li, T.; Quang, D.; Guan, Y. Network Propagation Predicts Drug Synergy in Cancers. Cancer Res. 2018, 78, 5446-5457. [CrossRef] 
20. Chen, D.; Liu, X.; Yang, Y.; Yang, H.; Lu, P. Systematic synergy modeling: Understanding drug synergy from a systems biology perspective. BMC Syst. Biol. 2015, 9, 56. [CrossRef]

21. Zhang, C.; Yan, G. Synergistic drug combinations prediction by integrating pharmacological data. Synth. Syst. Biotechnol. 2019, 4, 67-72. [CrossRef] [PubMed]

22. Chen, X.; Ren, B.; Chen, M.; Wang, Q.; Zhang, L.; Yan, G. NLLSS: Predicting Synergistic Drug Combinations Based on Semi-supervised Learning. PLoS Comput. Biol. 2016, 12, e1004975. [CrossRef] [PubMed]

23. Zhao, X.M.; Iskar, M.; Zeller, G.; Kuhn, M.; van Noort, V.; Bork, P. Prediction of drug combinations by integrating molecular and pharmacological data. PLoS Comput. Biol. 2011, 7, e1002323. [CrossRef] [PubMed]

24. Sun, Y.; Sheng, Z.; Ma, C.; Tang, K.; Zhu, R.; Wu, Z.; Shen, R.; Feng, J.; Wu, D.; Huang, D.; et al. Combining genomic and network characteristics for extended capability in predicting synergistic drugs for cancer. Nat. Commun. 2015, 6, 8481. [CrossRef]

25. Zhang, W.; Chen, Y.; Liu, F.; Luo, F.; Tian, G.; Li, X. Predicting potential drug-drug interactions by integrating chemical, biological, phenotypic and network data. BMC Bioinform. 2017, 18, 18. [CrossRef]

26. Yang, J.; Tang, H.; Li, Y.; Zhong, R.; Wang, T.; Wong, S.; Xiao, G.; Xie, Y. DIGRE: Drug-Induced Genomic Residual Effect Model for Successful Prediction of Multidrug Effects. CPT Pharmacomet. Syst. Pharmacol. 2015, 4, 91-97. [CrossRef]

27. Jaeger, S.; Igea, A.; Arroyo, R.; Alcalde, V.; Canovas, B.; Orozco, M.; Nebreda, A.R.; Aloy, P. Quantification of Pathway Cross-talk Reveals Novel Synergistic Drug Combinations for Breast Cancer. Cancer Res. 2017, 77, 459-469. [CrossRef]

28. Cheng, F.; Kovacs, I.A.; Barabási, A.L. Network-based prediction of drug combinations. Nat. Commun. 2019, 10, 1197. [CrossRef]

29. Cheng, F.; Lu, W.; Liu, C.; Fang, J.; Hou, Y.; Handy, D.E.; Wang, R.; Zhao, Y.; Yang, Y.; Huang, J.; et al. A genome-wide positioning systems network algorithm for in silico drug repurposing. Nat. Commun. 2019, 10, 3476. [CrossRef]

30. Reinhold, W.C.; Sunshine, M.; Liu, H.; Varma, S.; Kohn, K.W.; Morris, J.; Doroshow, J.; Pommier, Y. CellMiner: A web-based suite of genomic and pharmacologic tools to explore transcript and drug patterns in the NCI-60 cell line set. Cancer Res. 2012, 72, 3499-3511. [CrossRef]

31. Reinhold, W.C.; Mergny, J.L.; Liu, H.; Ryan, M.; Pfister, T.D.; Kinders, R.; Parchment, R.; Doroshow, J.; Weinstein, J.N.; Pommier, Y. Exon array analyses across the NCI-60 reveal potential regulation of TOP1 by transcription pausing at guanosine quartets in the first intron. Cancer Res. 2010, 70, 2191-2203. [CrossRef]

32. Tsherniak, A.; Vazquez, F.; Montgomery, P.G.; Weir, B.A.; Kryukov, G.; Cowley, G.S.; Gill, S.; Harrington, W.F.; Pantel, S.; Krill-Burger, J.M.; et al. Defining a Cancer Dependency Map. Cell 2017, 170, 564-576.e16. [CrossRef]

33. McFarland, J.M.; Ho, Z.V.; Kugener, G.; Dempster, J.M.; Montgomery, P.G.; Bryan, J.G.; Krill-Burger, J.M.; Green, T.M.; Vazquez, F.; Boehm, J.S.; et al. Improved estimation of cancer dependencies from large-scale RNAi screens using model-based normalization and data integration. Nat. Commun. 2018, 9, 4610. [CrossRef]

34. Hart, T.; Chandrashekhar, M.; Aregger, M.; Steinhart, Z.; Brown, K.R.; MacLeod, G.; Mis, M.; Zimmermann, M.; Fradet-Turcotte, A.; Sun, S.; et al. High-Resolution CRISPR Screens Reveal Fitness Genes and Genotype-Specific Cancer Liabilities. Cell 2015, 163, 1515-1526. [CrossRef]

35. Kanehisa, M.; Furumichi, M.; Tanabe, M.; Sato, Y.; Morishima, K. KEGG: New perspectives on genomes, pathways, diseases and drugs. Nucleic Acids Res. 2017, 45, D353-D361. [CrossRef]

36. Wishart, D.S.; Feunang, Y.D.; Guo, A.C.; Lo, E.J.; Marcu, A.; Grant, J.R.; Sajed, T.; Johnson, D.; Li, C.; Sayeeda, Z.; et al. DrugBank 5.0: A major update to the DrugBank database for 2018. Nucleic Acids Res. 2018, 46, D1074-D1082. [CrossRef]

37. Wang, Y.; Zhang, S.; Li, F.; Zhou, Y.; Zhang, Y.; Wang, Z.; Zhang, R.; Zhu, J.; Ren, Y.; Tan, Y.; et al. Therapeutic target database 2020: Enriched resource for facilitating research and early development of targeted therapeutics. Nucleic Acids Res. 2020, 48, D1031-D1041. [CrossRef]

38. Whirl-Carrillo, M.; McDonagh, E.M.; Hebert, J.M.; Gong, L.; Sangkuhl, K.; Thorn, C.F.; Altman, R.B.; Klein, T.E. Pharmacogenomics knowledge for personalized medicine. Clin. Pharmacol. Ther. 2012, 92, 414-417. [CrossRef]

39. Xia, P.; Xu, X.Y. PI3K/Akt/mTOR signaling pathway in cancer stem cells: From basic research to clinical application. Am. J. Cancer. Res. 2015, 5, 1602-1609.

40. Mihaylova, M.M.; Shaw, R.J. The AMPK signalling pathway coordinates cell growth, autophagy and metabolism. Nat. Cell. Biol. 2011, 13, 1016-1023. [CrossRef] 
41. Wang, J.; Chen, J.; Miller, D.D.; Li, W. Synergistic combination of novel tubulin inhibitor ABI-274 and vemurafenib overcome vemurafenib acquired resistance in BRAFV600E melanoma. Mol. Cancer Ther. 2014, 13, 16-26. [CrossRef] [PubMed]

42. Yuan, J.; Dong, X.; Yap, J.; Hu, J. The MAPK and AMPK signalings: Interplay and implication in targeted cancer therapy. J. Hematol. Oncol. 2020, 13, 113. [CrossRef] [PubMed]

43. El-Masry, O.S.; Al-Sakkaf, K.; Brown, B.L.; Dobson, P.R. Differential crosstalk between the AMPK and PI3K/Akt pathways in breast cancer cells of differing genotypes: Leptin inhibits the effectiveness of AMPK activation. Oncol. Rep. 2015, 34, 1675-1680. [CrossRef] [PubMed]

44. Inoki, K.; Li, Y.; Zhu, T.; Wu, J.; Guan, K.L. TSC2 is phosphorylated and inhibited by Akt and suppresses mTOR signalling. Nat. Cell Biol. 2002, 4, 648-657. [CrossRef] [PubMed]

45. Tao, R.; Gong, J.; Luo, X.; Zang, M.; Guo, W.; Wen, R.; Luo, Z. AMPK exerts dual regulatory effects on the PI3K pathway. J. Mol. Signal. 2010, 5, 1. [CrossRef]

46. He, G.; Zhang, Y.W.; Lee, J.H.; Zeng, S.X.; Wang, Y.V.; Luo, Z.; Dong, X.C.; Viollet, B.; Wahl, G.M.; Lu, H. AMP-activated protein kinase induces 533 by phosphorylating MDMX and inhibiting its activity. Mol. Cell. Biol. 2014, 34, 148-157. [CrossRef]

(C) 2020 by the authors. Licensee MDPI, Basel, Switzerland. This article is an open access article distributed under the terms and conditions of the Creative Commons Attribution (CC BY) license (http://creativecommons.org/licenses/by/4.0/). 